\section{Liquid Crystals}

\section{S. Chandrasekhar}

(Cambridge University Press, 1993, 450 pages).

ISBN: 0-521-417-473 (hardback);

0-521-427-41X (paperback)

Since the first edition of Chandrasekhar's book was published in 1977, liquid crystal devices have become ubiquitous and their use has increased to today's multibillion-dollar world market. Applications range from simple watch and calculator displays to large-area public display boards, and from pocket televisions to video recorders. Besides these technological advances, research on the physics and chemistry of liquid crystal materials has burgeoned, and the diversity of chemically stable materials has greatly increased the knowledge of the liquid crystal phase. Variations in the phases have been elucidated; for example, the discotic phases have been characterized, and new types of smectic phases have been discovered. Understanding of these materials has progressed but continues to be the subject of research in many laboratories worldwide. Therefore, this revised and updated edition of an already popular book is very welcome.

The book concentrates on the physics of thermotropic liquid crystal materials, a highly interdisciplinary field of research. Although readers are not exposed to the considerable research on the synthesis of these fascinating organic chemicals, chemical structures are presented where necessary. In addition, there is some mention of devices in which liquid crystals are used, but not a full description of liquid crystal applications since these are developing rapidly and detailed reference to them can quickly become dated. The book is comprehensive and self-contained in describing the physical properties of liquid crystals. Extensive references are included with each chapter, providing an invaluable source for researchers in the field, as well as an introduction for newcomers to liquid crystal research and for students wishing to read more on the subject. A minor criticism is that the contents page is rather difficult to read, making it hard to find a particular subject.

The most significant updates to the book were made on the previous version's final chapter on smectic liquid crystals, which has been substantially revised and now includes an additional chapter on discotic liquid crystals. The first chapters have been updated where necessary; for example, improvements in experiments using x-ray scattering now provide deeper understanding. The sec- ond and third chapters describe the statistical theories of the nematic phase and the extremely successful continuum theory of the nematic state. Newly included in the third chapter is a description of additional elastic constants, which may help to describe their importance in the flexoelectric effect and surface anchoring to alignment layers. The fourth chapter on cholesteric liquid crystals has been extended slightly, with a short section on the blue phases. The revised chapters also include brief descriptions of the twisted nematic (TN) and supertwisted nematic (STN) displays.

The fifth and substantially revised chapter tackles the smectic liquid crystal phases, which have more order than the nematic phase. A feature of the increased order is the formation of layers. Classification of smectic mesophases has progressed considerably, with improvement in $x$-ray sources; therefore, a table has been included to provide the structural classifications. A section has been added on smectic-A polymorphism and the phenomena of reentrant phases, where a nematic phase occurs in the middle of a smectic phase. A newly identified phase is the twisted grain boundary phase predicted by de Gennes, who recognized an analogy with superconductors; however, the phase was discovered by Goodby et al. The section on the smectic- $C$ phase has been expanded because of the great deal of work done on this phase, particularly since ferroelectricity was demonstrated by Meyer et al. in 1975. The defect structures are described, and there is a discussion of the continuum theory for smectic-C liquid crystals, although this is presently an area of active research. Applications are also mentioned briefly at the end of the chapter.

The final and new chapter describes the physics of the discotic mesophases, which have emerged only in the last decade. An understanding of the disklike molecules and their self-assembled structures owes much to the previous work, even though these molecules differ in shape from the rodlike calamitic liquid crystals described in the previous chapters. The new chapter describes the application of the continuum theory and the results of x-ray scattering and light scattering, and includes explanations of the defect structures that occur in the columnar phases, and a description of the nematic discotic phase. The chapter concludes with a section on biaxial nematic liquid crystals, which were predicted by Chandrasekhar himself

Because the field of liquid crystals has expanded greatly since Chandrasekhar first published his book in 1977, it is impossible to include all the exciting new areas of research, such as the nonlinear optical properties of liquid crystals. Nonetheless, the book is a useful, interesting, and thorough treatise on the physics of the many different liquid crystal phases.

Reviewer: Sally E. Day is in the Department of Electronic and Electrical Engineering at the University College London, England.

\section{Introduction to Mineral Sciences}

\section{A. Putnis}

(Cambridge University Press, 1993

450 pages).

ISBN: 0-521-419-220 (hardback):

0-521-429-471 (paperback)

In this excellent book, Putnis adopts a materials science approach to the study of minerals and focuses on their behavior in relation to geological processes, rather than using the traditional systematic treatment of the subject. The approach is more qualitative than quantitative, but the complex concepts of materials behayior are clearly explained and extremely well-illustrated.

The introductory chapters deal with the basic concepts of crystallography and symmetry. The ideas behind crystalline anisotropy are clarified, and the basis of the optical, elastic, and related tensorial properties of minerals is presented. An extensive chapter on diffraction and imaging techniques follows, including the reciprocal lattice, powder and singlecrystal x-ray diffraction, electron diffraction, and imaging. A final methodology chapter on spectroscopy comprehensively covers the concepts involved in nuclear magnetic resonance spectroscopy, electron spin resonance spectroscopy, vibrational spectroscopy, inelastic neutron scattering, optical spectroscopy, $x$-ray spectroscopy, and the Mössbauer effect.

Most of the book, however, is devoted to the nature and behavior of minerals. This ranges from discussion of the basic principles of crystal architecture (i.e., close packing and polyhedral packing) to the structural features of major rockforming phases such as the olivines, pyroxenes, and framework silicates. The concept of defects and their role in mineral behavior are introduced, illustrated by specific references to systems such as the plagioclase feldspars and spinels.

The basic ideas behind thermodynamics, which determine most aspects of mineral behavior, are clearly presented and include discussions of entropy, phase equilibria, and Landau theory. The nature of solid solutions is outlined, and 
the processes of exsolution, spinodal decomposition, and ordering are reviewed. Kinetics are finally introduced, and the book concludes with excellent case studies of transformation processes and discussions of the incommensurate behavior in quartz, unmixing in the pyroxene system, and other geologically and materials-relevant processes.

In summary, this book illustrates the major advances in our understanding of the complex behavior of minerals and related phases. It could have been written only by a scientist who has an extensive and clear understanding of modern mineralogy. Andrew Putnis should be congratulated for writing this outstanding book, which will not be surpassed for many years.

Reviewer: G.D. Price is a professor in the Geology Department at the University College London, England.

\section{Books}

Since the MRS Bulletin receives many more publications than can be reviewed, starting this month the Bulletin will run a separate list of recently published books and new journals relevant to materials science that have come to our attention. Reviews of some of the books listed here may appear in future issues of the Bulletin.

Advances in Multi-Photon Processes and Spectroscopy-Volume 7, S.H. Lin, ed. World Scientific Publishing, Singapore, 1991. 311 pp, $h c$, ISBN 981-02-0718-2.

Biomaterials-Novel Materials from Biological Sources, D. Byrom, ed. Stockton Press, New York, 1991. 365 pp, hc, ISBN 1-56159-037-1

Characterization of Advanced Materials, W. Altergott and E. Henneke, eds. Plenum Press, New York, 1991. 183 pp, $\$ 69.50 \mathrm{hc}$, ISBN 0-306-43837-2.

Compaction, Quality Control, and Training, Volume 1, Advances in Powder Metallurgy-1991, compiled by L.F. Pease III and R.J. Sansoucy. Metal Powder Industries Federation, New Jersey, 1991. $312 \mathrm{pp}, h c$, ISBN 1-878954-08-3.

Electrical and Magnetic Methods of Nondestructive Testing, J. Blitz. Adam Hilger imprint by Institute of Physics, United Kingdom. 237 pp, $\$ 90.00 h c$, ISBN 0-7503-0148-1.

Elementary Physicochemical Processes on Solid Surfaces, V.P. Zhdanov. Plenum Press, New York, 1991.314 pp, $\$ 85.00 \mathrm{hc}$, ISBN 0-306-43779-1.
Papers published in the most recent issue of .....

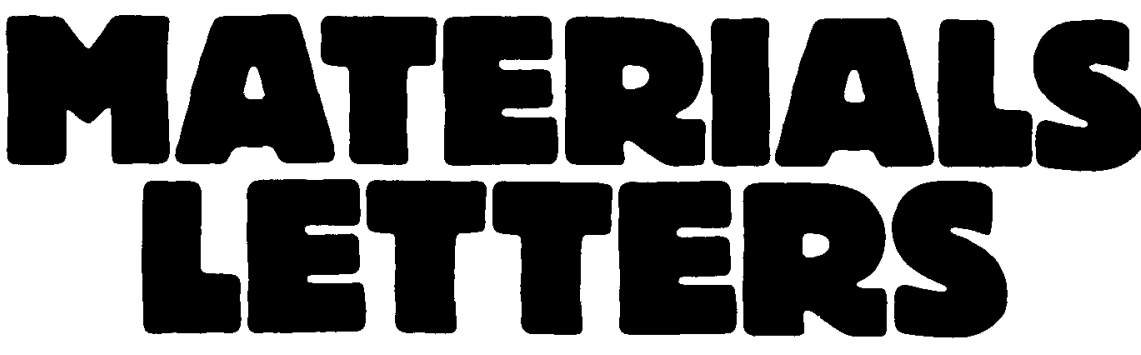

\section{Contents of Volume 16, number 6, June 1993}

Reaction Paths During Melt Texturing of $\mathrm{YBa}_{2} \mathrm{Cu}_{3} \mathrm{O}_{7-\mathrm{x}}$ S. Karabashev and Th. Wolf

Studies on the Behavior of the Roughness of the Fracture Surfaces of Silica Glass R. Ham-Su and V.M. Castaño

Structural Properties of the System $\mathrm{Al}_{2} \mathrm{O}_{3}-\mathrm{Cr}_{2} \mathrm{O}_{3}$ M. Ristić, S. Popović and S. Musić

Critical Current in Electrophoretically Deposited Thick Films of YBCO Superconductor

D. Bhattacharya, S.N. Roy, R.N. Basu, A. Das Sharma and H.S. Maiti

Preparation of High- $\mathrm{T}_{\mathrm{c}}$ Superconducting $(\mathrm{Bi}, \mathrm{Pb})_{2} \mathrm{Sr}_{2} \mathrm{Ca}_{2} \mathrm{Cu}_{3} \mathrm{O}_{\mathrm{y}}$ Phase via an Oxalate Route

H.S.W. Chang, S.R. Sheen, D.H. Chen, C.T. Chang, C.H. Kao, J.C. Huang, Y.C. Chou, Y.C. Hsieh, Y.H. Hsieh and M.K. Wu

Characterization of the Microstructure in TiB-whisker Reinforced Ti Alloy Matrix Composite

$$
\text { D.X. Li, D.H. Ping, Y.X. Lu and H.Q. Ye }
$$

Characterization of $\mathrm{TiB}_{2}-\mathrm{Ti}(\mathrm{CN})-\mathrm{Ni}$ Ceramics by Transmission and Analytical Electron Microscopy

$$
\text { J.Y. Dai, D.X. Li, H.Q. Ye, G.J. Zhang and Z.Z. Jin }
$$

Properties of $\mathrm{Au} / \mathrm{SiO}_{2} / \mathrm{a}-\mathrm{Si}: \mathrm{H}$ Solar Cells with Wet Oxide

H. Gleskova, V.A. Skryshevsky, J.N. Bullock, S. Wagner and J. Stuchlik

Wavelength-selective Transmission in Transition Metal Containing Silica Gel Monoliths

S. Roy and D. Ganguli

Interfacial Cracking During Thermal Oxidation in a $30 \mathrm{Vol} \%$ SiC-whisker Reinforced Alumina

W. Deqing and H.F. Lopez

The Decomposition of $\mathrm{YBa}_{2} \mathrm{Cu}_{3} \mathrm{O}_{7-x}$ at Low Oxygen Pressures J.S. Kim and D.R. Gaskell

Preparation and Crystal Structure of $\mathrm{C}_{60} \mathrm{~S}_{8} \mathrm{CS}_{2}$, a New Fullerene-containing Heteromolecular Solid

G. Roth, P. Adelmann and R. Knitter

For a free sample copy of this issue contact:

ELSEVIER SCIENCE PUBLISHERS, PO Box 103, 1000 AC Amsterdam, The Netherlands Tel: 3120 5862819, Fax: 31205862580

For information on a personal subscription contact the MRS by using the Reader Service Card. 
Fundamental Aspects of Inert Gases in Solids, NATO ASI Series B \#279, S.E. Donnelly and J.H. Evans, eds. Plenum Press, New York, 1991. 473 pp, $\$ 125.00 h c$, ISBN 0-306-44051-2.

Fundamental Aspects of Heterogeneous Catalysis Studied by Particle Beams, NATO ASI Series B \#265, H.H. Brongersma and R.A. van Santen, eds. Plenum Press, New York, 1991. 462 pp, $\$ 120.00 h c$, ISBN 0-30644002-4.

Gaseous Dielectrics VI, L.G. Christophorou and I. Sauers, eds. Plenum Press, New York, 1991. 651 pp, \$129.50 hc, ISBN 0-306-43894-1.

Growth of Crystals-Volume 17, E.I. Givargizov, S.A. Grinberg, eds. (translated by D.W. Wester). Consultants Bureau, New York, 1991. 216 pp, \$95.00 hc, ISBN 0-30618117-7.

Hydrogen in Semiconductors, Proc. 6th IUPAP-ICTP Semiconductor Symposium, Trieste, Italy, August 27-31, 1990, M. Stutzmann and J. Chevallier, eds. NorthHolland, The Netherlands, $1991.581 \mathrm{pp}$, $\$ 214.50 h c$, ISBN 0-444-89138-2.

International Encyclopedia of

Composites-Volume 4, S.M. Lee, ed. VCH Publishers, New York, 1991. 532 pp, \$275.00 $h c$, ISBN 3-527-27950-4.

Ion Beam Modification of Materials, Parts I and II, Proc. 7th Intl. Conf. on Ion Beam Modification of Materials, Knoxville, Tennessee, September 9-14, 1990, S.P. Withrow and D.B. Poker, eds. North-Holland, The

Netherlands, 1991. 1,500 pp, $\$ 571.50$

(2 vols.) hc, ISBN 0-444-89200-1.

Japanese/American Technological Innovation-The Influence of Cultural Differences on Japanese and American Innovation in Advanced Materials, W.D. Kingery, ed. Elsevier Science Publishing, New York, 1991. 290 pp, $h c$, ISBN 0-444-01633-3.
Light Scattering in Semiconductor Structures and Superlattices, NATO ASI Series B \#273, D.J. Lockwood and J.F. Young, eds. Plenum Press, New York, 1991. 603 pp, $\$ 135.00 h c$, ISBN 0-306-44036-9.

Modern Topics in Electron Scattering, B. Frois and I. Sick, eds. World Scientific Publishing, Singapore, 1991.797 pp, $h c$, ISBN 9971-50-975-X.

Parts Production Technologies, Volume 3, Advances in Powder Metallurgy-1991, compiled by L.F. Pease III and R.J. Sansoucy. Metal Powder Industries Federation, New Jersey, 1991. 274 pp, hc, ISBN 1-878954-10-5.

Periodic Precipitation, H.K. Henisch. Pergamon Press, United Kingdom, 1991. 122 pp, $\$ 41.00 h c$, ISBN 0-08-040276-3.

Phase Transitions in Surface Films 2, NATO ASI Series B \#267, H. Taub, G. Torzo, H.J. Lauter, and S.C. Fain Jr., eds. Plenum Press, New York, 1991.507 pp, $\$ 125.00$ hc, ISBN 0-306-44005-9.

Physical Acoustics-Fundamentals and Applications, O. Leroy and M.A. Breazeale, eds. Plenum Press, New York, 1991. 737 pp, $\$ 139.50 h c$, ISBN 0-306-43883-6.

Polymers: Chemistry and Physics of Modern Materials, 2nd edition, J.M.G. Cowie. Chapman \& Hall, New York, 1991. 436 pp, \$39.95 pb, ISBN 0-216-92980-6.

Powder Injection Molding, Volume 2, Advances in Powder Metallurgy-1991, compiled by L.F. Pease III and R.J. Sansoucy. Metal Powder Industries Federation, New Jersey, 1991. 346 pp, hc, ISBN 1-878954-09-1.

Principles of Extractive Metallurgy, $2 n d$ edition, A. Ghosh and H.S. Ray. Wiley Eastern Limited, India, 1991. $302 \mathrm{pp}, h c$, ISBN 81224-0322-0.
Resonant Tunneling in SemiconductorsPhysics and Applications, NATO ASI Series $B \# 277$, L.L. Chang, E.E. Mendez, and C. Tejedor, eds. Plenum Press, New York, 1991. 537 pp, \$129.50 hc, ISBN 0-306-44048-2.

Science and Technology of Nanostructured Magnetic Materials, NATO ASI Series B \#259, G.C. Hadjipanayis and G.A. Prinz, eds. Plenum Press, New York, 1991.720 pp, $\$ 149.50$ hc, ISBN 0-30643924-7.

Semimagnetic Semiconductors and Diluted Magnetic Semiconductors. M. Averous and M. Balkanski, eds. Plenum Press, New York, 1991. 274 pp, $\$ 79.50 \mathrm{hc}$, ISBN 0-306-43931-X.

Sintering, Volume 4, Advances in Powder Metallurgy-1991, compiled by L.F. Pease III and R.J. Sansoucy. Metal Powder Industries Federation, New Jersey, 1991. 226 pp, hc, ISBN 1-878954-11-3.

Solid Polymer Electrolytes-Fundamentals and Technological Applications, F.M. Gray. VCH Publishers, New York, 1991. 245 pp, $h c$, ISBN 3-527-27925-3.

Solid State Physics-Volume 45, H. Ehrenreich and D. Turnbull, eds. Academic Press, California, 1991. 295 pp, $h c$, ISBN 0-12-607745-2.

Supercollider 3, J. Nonte, ed. Plenum Press, New York, 1991. 1,221 pp, $\$ 185.00 \mathrm{hr}$, ISBN 0-306-44037-7.

Theoretical Heterogeneous Catalysis, Volume 5, World Scientific Lecture and Course Notes in Chemistry, R.A. van Santen. World Scientific Publishing, Singapore, $1991.396 \mathrm{pp}, h c$, ISBN 9810203845.
Beam-Solid Interactions - Fundamentals and Applications (Vol. 279)

$\$ 58$ MRS Members \$67 U.S. List \$77 Foreign

Semiconductor Helerostructures for Photonic and Electronic Applications ( $\mathrm{Vol}$. 281)

\$58 MRS Members \$67 U.S. List \$77 Foreign

Chemical Perspectives of Microelectronic

Materials III (Vol. 282)

\$58 MRS Members \$67 U.S. List \$77 Foreign

Microcrystalline Semiconductors - Materials

Science \& Devices (Vol. 283)

$\$ 60$ MRS Members \$69 U.S. List \$79 Foreign

Laser Ablation in Materials Processing -

Fundamentals and Applications (Vol. 285)

\$55 MRS Members \$63 U.S. List \$72 Foreign

\section{Just Published!}

Symposium Proceedings from the 1992 Fall Meeting

Nanophase and Nanocomposite Materials

(Vol. 286)

$\$ 55$ MRS Members \$63 U.S. List \$72 Foreign

Silicon Nitride Ceramics - Scientific and

Technological Advances (Vol. 287)

\$55 MRS Members \$63 U.S. List \$72 Foreign

HIgh-Temperature Ordered Intermetallic Alloys V (Vol. 288)

$\$ 60$ MRS Members \$69 U.S. List \$79 Foreign

Flow and Microstructure of Dense Suspensions

(Vol. 289)

\$60 MRS Members $\$ 69$ U.S. List $\$ 79$ Foreign

Dynamics in Small Confining Systems (Vol. 290)

$\$ 60$ MRS Members \$69 U.S. List \$79 Foreign

Materials Theory and Modelling (Vol, 291)

$\$ 60$ MRS Members \$69 U.S. List \$79 Foreign
Biomolecular Materials (Vol. 292)

$\$ 60$ MRS Members \$69 U.S. List \$79 Foreign

Solid State Ionics III (Vol. 293)

$\$ 60$ MRS Members \$69 U.S. List \$79 Foreign

Scientific Basis for Nuclear Waste Management XVI (Vol. 294)

$\$ 55$ MRS Members \$63 U.S. List \$72 Foreign

Atomic-Scale Imaging of Surfaces and Interfaces (Vol. 295)

\$60 MRS Members \$69 U.S. List \$79 Foreign

Structure and Properties of Energetic Materials

(Vol. 296)

$\$ 60$ MRS Members \$69 U.S. List $\$ 79$ Foreign Order from: Materials Research Society

9800 Mcknight Road, Pittsburgh, PA 15237 U.S.A. Phone (412) 367-3012, FAX (412) 367-4373 